\title{
CONSIDERAÇÕES SOBRE A NOMINALIZAÇÃO EM PORTUGUES
}

\section{CARLOS ALBERTO faraco}

Este estudo é uma apresentação de alguns problemas envolvidos na descrição gramatical de frases nominais da língua portuguesa ditas nominalizadas. Faço uma seleção de dados empíricos e, com base nestes, uma discussão de modelos descriivos gerativo-transformacionais. A não ser em breves referências, não entro ainda (o que deixo para outro estudo) na abordagem lexicalista dos mesmos fenômenos.

Interessam-me neste estudo aqueles fenômenos que na lingüística contemporânea se convencionou reunir' sob o título de Nominalização. Dentre as muitas estruturas envolvidas sob es'e título, selecionei - para efeitos deste estudo - dois tipos, exemplificados em (1) e (2) $)^{1}$ :

(1) A vinda dos meninos (atrapalhou nossos planos)

(2) A destruição da cidade pelos inimigos (atrapalhou nossos planos) e que podem ser assim caracterizadas²:

(3) (a) e'es têm a configuração superficial

(1) Ait. $-\mathrm{N}-$ de $+\mathrm{FN}$

(2) Art. $-\mathrm{N}-$ de $+\mathrm{FN}-$ port $\mathrm{FN}$;

(b) o item lexical que substitui $N$ é relacionado com um verbo (digamos que ele é a contraparte nominal dum verbo). Desse modo, vinda em (1) e destruição em (2) estão em relação com os verbos vir e destruir, respectivamen$\mathrm{te}^{3}$;

(c) a sentença e a frase nominal, contendo respectivamente verbo e nominal aparentados, também se relacionam entre si pelo fato de as mesmas relações que se instauram 
entre o verbo e os demais constituintes duma sentença poderem se instaurar entre o nominal e os demais constituintes duma FN. Nestes termos, (4) se re'aciona com

(1), como (5) com (2):

(4) Os meninos vieram

(1) A vinda dos meninos

(5) Os inimigos destruíram a cidade

(2) A destivição da cidade pelos inimigos

Tanto assim é que se pode definir uma mesma relação (digamos, agente/açāo) entre cs meninos e vieram em (4) e entre os meninos e vinda em (1), bem como entre os inimigos e destruiram em (5) e os inimigos e destruição em (2). Do mesmo modo, entre destruiçāo e a cidade em (5) pode-se definir uma relação (digamos, ação/paciente) a qual também ocorre entie destruiçăo e a cidade em (2). Esta similitude em termos de relações é bastante interessante e nos permite espetacular não só quanto à estrutura interna da sentença e da frase nominal, como quanto às relaçōes entre elas.

Desta caracterização - posta em termos bastante gerais - é possível destacar três espécies de relação:

(6) (a) entre itens lexicais:

vir - vinda

(b) entre constituintes duma estrutura:

- na frase nominal

os meninos - vinda

os inimigos - destruição

$>$ (agente/ação)

destruição - cidade (ação/paciente)

- na sentença

os meninos - vieram

os inimigos - destruíram

destruíram - a cidade (ação/paciente)

(c) entre estruturas ( $\mathrm{S}$ e $\mathrm{FN}$ )

os meninos vieram - a vinda dos meninos

os inimigos destrulram a cidade - a destruição da cidade 
O que temos resumido em (6) é - na verdade - um complexo de relaçōes, na medida em que a explicação de uma das espécies determina (ou é determinada pela) explicação que se oferecer para as demais: pode-se formular tanto uma hipótese na qual a relação entre as estruturas (6.c) é que explica (6.a); quanto uma em que é a relação entre os itens lexicais (6.a) que explica (6.b) e (6.c). De qualquer modo, só será de valor lingüisticamente a análise de 1) e (2) que der conta, com simplicidade e generalidade, das três espécies de relação em pauta.

Este complexo de relaçóes - levantado a partir de uma reflexão informal em torno de estruturas como (1) e (2) - é o núcleo deste irabalho: a discussão se fará sempre na perspectiva das três relações (entre itens lexicais; entre constituintes; entre estruturas).

Estruturas como (1) e (2) constituem, portanto, um problema lingüístico interessante: elas envolvem aspectos cruciais da onálise das líriguas humanas, desde relações lexicais até a própria organização da gramátíca.

A consciência dos diversos aspectos deste problema não é nova nos estudos lingüísticos. Com o objetivo de mostrar isto, vou fazer, a seguir, breve referência a alguns destes estudos, antes de entrar no quadro teórico de sustentação deste trabalho.

A relação entre itens lexicais apresentada acima. (3.b/6.a) tem sido tratada, tradicionalmente, sob o título de Morfologia. Desta se diz que é o estudo da classificação, estrutura e formação das palavias, estando, neste último caso, a derivação, apresentada como o processo pelo qual de uma palavra se forma outras, quer mediante c acréscimo de um afixo ao radical (derivação afixal); quer mediante a redução da palavra derivante (derivação regressiva); quer, ainda, mediante a simples mudança de classe gramatical (derivação imprópria) (cf. Cunha, 1970: 42-53). Assim, itens lexicais como destruir e destruiçáo; amparar e amparo;vir e vinda se relacionam, por ser - segundo item de cada par obtido do primeiro por derivação (afixal, regressiva e imprópriva, respectivamente). Este processo é tomado como um dos responsáveis pela constituição das chamadas famílias de palavras (cf. Cunha, op. cit.: 42).

Passando, agora, para as relações entre constituintes da FN (cf. 6.b), encontramos na gramática tradicional a distinção de duas delas, as quais definiam as funções sintáticas de adjunto adnominal 
(AA) e complemento nominal (CN). A gramática iradicional, porém, estava limitada à palavra e à sentença (cf. Lyons, 1968, cap. 5): à morfologia se reservava o estudo da primeira; e à sinfaxe, o estudo da segunda. Havia, portanto, uma única unidade sintática: a, sentença. As funçōes de $A A$ e $C N$, embora sendo definidas por relações entre constituintes duma mesma FN (cf. Lima, 1972: 210 e 224) - o que vale dizer, relações internas à $F N$ - eram tomadas como funções sintáticas da sentença ( $C N$ era um termo integrante da oração e $A A$, um termo acessó:io. (cf. Lima, op. cit.: 209 e 224). Operando, assim, com um só nivel sintático (a sentença), o gramático não tinha condições de destacar outras relações dentro da FN, como - por exemflo - aquela que, em (7), se estabelece entre na semana passada e os demais constifuintes da FN, relação esta diferente da que se estabelece entre a mesma locução - na semana passada - e os outros constituintes em (8):

(7) A organização dos arquivos na semana passada facilitou nosso trabalho

(8) A organização dos arquivos facilitou, na semana passada, nosso trabalho

Em ( 7$)$, o elemento sublinhado se relaciona com a organização dos arquivos, enquanto em (8), com facilitou nosso trabalho. Em qualquer caso, porém, ele seria um adjunto adverbial de tempo da sentença, pela gramática tradicional.

Se a sentença era tida como o único nível sintático, não é de se estranhar o fato de as relações entre estruiuras (especificamente para nós, entre $F N$ com nominal de ação e $S$ com o verbo correspondente ao nominal, cf. 6.C) não terem sido tratädas explicitamente. Contudo, são de valor certas intuições reveladas a respeito disto ras gramáticas. E, aqui, vão alguns textos como testemunhas, os quais ouso interpretar, situando-os na linha de problemas que vimos discutindo.

a) "...: 'obediência do aluno'. E claro que, nesta frase, aluno pratica a ação de obedecer". (Almeida, 1967, cap. XLVIII)

Em outros termos, aluno é sujeito da ação expressa em obediência, já que num dos conceitos que se dava de sujeito, na gramática tradicional, este é o ser que pratica a ação expressa pelo verbo (cf. Cunha, 1970: 63). Embora obediência não seịa verbo, está expressando também uma açāo. De certa forma, o gramático está percebendo uma relação idêntica entre aluno-obediência e aluno-obedecer; em última análise, entre FN e S. 
b) Em Torres (1961: 206), uma palavra como obediência recebe a qualificação de "... palavra que tem força de verbo".

O gramático parece revelar a apreensão de certa identidade de desempenho do verbo e do nome; provavelmente esta força se refere à possibilidade de ambos instaurarem relações análogas com os outros constituintes das respectivas estruturas em que ocorrem.

c) um outro texto: "a) A invenção de palavras caracteriza o estilo de Guimarães Rosa (... : palavras é o objeto, a coisa inventada, o paciente da ação contida no substantivo invenção - aqui usada, portanto, transitivamente)" (Lima, 1972: 211)

Outra vez, o que se percebe é uma relação entre invenção $e$ palavras que é a mesma que se pode estabelecer entre inventar e! palavras. Daí, a preocupação com o conceito de transitividade, a se aplicar tanto a verbos quanto a substaniivos (cf. Lima, op. cit.: 21011).

Neste ponto, é interessante observar que os gramáticos tradicionais em geral justificam as relações que estou apontando entre FN e $S$ (6.c), com base na morfologia, i.e., nas relações de parentesco lexical das palavras envolvidas.

Dito diferentemente, é pelo fato de, por exemplo, conhecer e conhecimento serem palavras da mesma família' e conhecer ser um verbo transitivo, que se explica a ocorrência de um constituinte na função de complemento nominal junto a conhecimenio. Veja-se como confirmação, este trecho de Lim a(1972: 211$)$ a respeito dos substantivos que são acompanhados de complemento nominal (em oposição aos que 0 são de adjunto adnominal):

"... ० substantivo abstrato de ação, correspondente a ve:bo da mesma família que exija objeto (direto, oú indireto), ou complemento circunstancial:

inversão da ordem (cf. inverter a ordem - objeto direito); obediência aos pais (cf. obedecer aos pais - objeto indireto); ida a Roma (cf. ir a Roma - complemento circunstancial)".

A respetio ainda das relações entre estruturas, é indispensável referir-se à consciência deste problema em Jespersen.

Diante de dados como:

(8) O doutor chegou

(9) Eu vi que o dou:or chegou 
(10) Eu vi o douior chegar

(11) Eu vi a chegada do doutor

ele diz que a relação entre as duas idéias 'doutor' e 'chegar' é fundamentalmente a mesma nas quatro combinaçōes (cf. Jespersen, 1924: 149). E, adiante (p. 185), numa retomada do assunto, ele destaca a equiva'ência entre estruturas: "J'ai vu l'arrivé du docteur est équivalent à J'vai vu le docteur arriver ef à J'ai vu que le docteur arrivait, ..."

A visão de Jespersen é, de certa forma, mais rica que a que vimos na gramática tradicional. Ele supera os limites impostos por um estudo como o desta gramática (baseado em apenas duas unida des: palavras e sentenças), porque ele opera com a noção de dependência, relaçāo que se esbelece entre as palavras dum conjunto qualquer (e não apenas daquele conjunto que se designaria por seniença). Ele pode, então, apreender um número de "unidades" e inter-relacioná-las - como é o caso da apreensão de relações entre os exemplos (8) a (11).

A classificação das palavras por Jespersen em ranks, i.e., grupos de palavras constituiídas pelo tipo de relação - palavras defimidoras ou pa!avras definas - que elas podem ter com outras numa combinação qualquer (cf. Jespersen, op. cit.: 119 e seg.); e a possibilidade de elas mudarem de grupo - determinando com isto, um movimento idêntico das outras palavras com elas relacionadas (cf. Jespersen, op. cit.: 186) - revela uma sintaxe muito mais flexi. vel que a tradicional.

Daqui para frente, discutirei as relações entre itens lexicais, entre constifuintes duma estruiura, e entre estruturas - levantadas a partir dos exemplos

(1) A vinda dos meninos (atrapalhou nossos p!anos)

(2) A destruiçāo da cidado pelos inimigos (atrapalhou nossos planos)

(4) Os meninos vieram

(5) Os inimigos destruíram a cidade

e sintetizados em (6). acima - assumindo como fundamento a teoria gerativo-transformacional. ${ }^{6}$

Há, na lingüistica gerativo-transformacional, duas hipółeses diferentes (H. 1 e H. 2) para dar conta de esiruturas como (1) e (2): 
H. 1: A esirutura profunda que subiaz a uma $F N$ como (1) e (2) é idêntica à que subjaz a uma $S$ como (4) ou (5). A diferença superficial se deve a diferentes processamentos da estrutura profunda pelo subcomponente transformacional.

H. 2: A estruivia profunda que subjaz a uma $F N$ como (1) ou (2) é diferente da que subjaz a uma $S$ como (4) ou (5). A semelhança qu se percebe entre $F N$ e $S$ se deve - basicamente - ao fato de elas conterem itens relacionados no léxico.

A primeíra hipótese é chamada de transformacionalista (a base gera uma estruiura profunda com as mesmas ca:acterísticas, havendo regras específicas, no subcomponente transformacional, para superficializá-la como $\mathrm{FN}$ ou como S); e a segunda de lexicalista (o subcomponente :ransformacional perde aquelas regras de nominalização; a base gera estruturas profundas diferentes - uma nominal, outra sentencial - esiando os itens lexicais intimamente relacionados no. léxico). ${ }^{7}$

Dito de outro modo, a relação entre $F N$ e $S-(1)$ e (4), (2) @ (5) - tem explicações dife:entes:

a) Fara os postuladores da hipótese transformacionalista, as semelhanças se devem ao fato de ambas as es:ruturas superficiais serem derivadas transformacionalmente duma estrutura profunda com as mesmas características;

b) para os postuladores da hipótese lexicalista, as semelhanças se devem ao fato de ambas as estruturas superficiais - embora derivadas de estruturas profundas diferentes conterem itens lexicais aparentados. Deve-se, destacar, também que as estruturas profundas - embora diferentes têm aspectos em comum. Assim, as semelhanças entre FN e $S$ se explicam, em princípio, pelo parentesco dos itens no léxico, mas também por analogia formal das estruturas profundas que os contêm.

Concluindo: se retornarmos aos três tipos de relações visto em (6): entre itens lexicais (6.a), entre constituintes duma estrutura (6.b), entre estruturas (6.c) - veremos que um iransformacionalista dirá que a relação entre $S$ e $F N$ (6.c) se explica por ambas terem idêntica estrutura profunda. Isto também explica as relações entre os constituintes (6.b), já que é no nível da estrutura profunda que elás se definem (cf. Chomsky, 1965: § 2.2.). Dependendo do conjunto de 
regras transformacionais que se aplicam (no nosso caso específico, se as regras de nominalização forem escolhidas), poderemos motivar - via subcomponente transformacional - a introdução, na estrutura, de itens lexicais derivados (de:ivação no sentido da morfologia tradicional) - relação des'acada em (6.a). O nominal de ação é, nestes termos, a forma que o verbo toma se a $S$ onde ele está. for nominalizada.

Um lexicalista, ao contrário, dirá que a re!ação entre $S$ e $F N$ (6.c) se explica po:que elas têm itens lexicais que se relacionam no léxico (6.a) por compartilharem certas propriedades quanto às relações que eles podem instaurar com os demais constituintes (6.b) das estruturas em que entram, as quais, embora diferentes, têm propriedades comuns.

A hipótese H. Iprecedeu, no tempo, a H. 2. A partir do modelo de Chomsky (1965) - no qual se dividiu a base num subcomponente categorial e num lexical; e se introduziram os traços sintáticos - criaram-se, segundo Chomsky (1967: 188), condiçōes para a formulação duma hipótese como a lexicalista.

O p:imeiro texto em que se formula em detalhes uma análise transformacionalista para estruturas como

(1) A vinda dos meninos (atrapalhou nossos p!anos)

(2) A destruiçāo da cidade pelos inimigos (atrapalhou nossos planos)

é Lees (1960).

Ele observa que:

a) é possível produzir sempre novos nominais (estruturas como (1) e (2), entre outras ${ }^{8}$ ); (Lees, op. cit.: XVII);

b) na estrutura de tais nominais, são apreensiveis relaçōes sintáticas encontradas em sentenças (op. cit. XVIII) ${ }^{3}$

Lees, então, conclui que os fatos observados motivam a procuiz duma formulação mais parcimoniosa da gramática (uma formulação que relacione $\mathrm{FN}$ e S), a'cançável pela incorporação nesta de regras que convertem estruturas de base (terminal strings) em estruturas nominais de várias formas, dando conta, assim, das relações entre as estruiuras (op. cit.: XIX).

Lees se propōe a explicitar as regras sintáticas de conversão de estruturas de base em estruturas nominais. Assim, seria de cará- 
ter puramente sintático a relação entre estas estruturas: a estrutura nominal de superficie, contendo item lexical derivado, seria obtida de estruturas de base por meio de transformações específicas.

As transformações de nominalização eram, no modelo de Syntactic Structures (com o qual opera Lees), generalizadas. Estas - diferentemente das singulares que se aplicavam a uma só $S$ - convertiam um par de sentenças numa única sentença, encaixando uma parte ou o todo duma $S$ na outra, ou conjugando-se. Por meio destas transformações se dava conta do fenômeno da recursividade, i.e., da possibilidade de engendramento infinito de estruturas encaixadas ou conjugadas pela reaplicação sucessiva das regras ${ }^{10}$.

Tomemos - para exemplificar - a estrutura (1):

(1) A vinda dos meninos (atrapalhou nossos planos)

e formulemos uma análise fundamentada na proposta de Lees. Uso o seguinte fragmenio de giamática, adaptado a partir de Lees (1960: 41):

$$
\begin{aligned}
& S \rightarrow F N \text { FV } \\
& F N \rightarrow \text { Det } \quad\left\{\begin{array}{c}
\mathrm{Na} \\
\mathrm{N}
\end{array}\right\} \\
& \text { FV } \rightarrow \text { Aux V } \\
& \text { Det } \rightarrow \text { (Pré-art) Art } \\
& \text { Aux } \rightarrow T \\
& V \rightarrow \quad\left\{\begin{array}{ll}
\text { Vin } & \text { (Maneira) } \\
\text { Vir } & \text { FN }
\end{array}\right\} \\
& T \rightarrow \quad\left\{\begin{array}{l}
\text { presente } \\
\text { passado }
\end{array}\right\} \\
& M \rightarrow \text { Adj-mente }
\end{aligned}
$$

\section{OBSERVAÇOES:}

1. O símbolo Na está para nome abstra:o: é o 'buraco' na estrutura encaixante para receber - via transformação generalizada - a $S$ nominalizada;

2. Adiante no texto, aparece NML (símbolo para morfema de nominalizaçáo); $Y$ (corresponde ao resto da sentença encai$x a n ! e) ; X$ e $Z$ podem ser nulos.

Em Lees (op. cit.: 67-8), há a regra de transformação generalizada número 7 (GT 7) para dar conta de nominais de ação correspondentes a verbos intransitivos (vinda - vir). Reproduzo aqui a 
regra, adaptando-a pa:a os fatos do português:

(GT 7 )

$\left(\mathrm{S}_{1}\right) X-\mathrm{Art}-\mathrm{Na}-\mathrm{Y}$

$\left(S_{3}\right) X-A r_{i}-N M L+V i n(+A d j)+d e+F N-Z-Y$

Explicitando: dadas duas $S_{s}\left(S_{1}, S_{2}\right)$ com as descrições estruturais apresentadas acima, obtém-se uma só $S\left(S_{3}\right)$ :

I: fazendo mudanças estruturais em $S_{2}$, ou seja:
a) apagando $T$;
b) introduzindo NML junto de Vin;
c) mudando Adj-mente para Adj;
d) pospondo $\mathrm{FN}$ a NML + Vin;
e) inserindo de entre NML + Vin e FN.

II: encaixando $S_{2}$ assim transformada em $S_{1}$ :

a) substituindo $\mathrm{Na}$ de $S_{1}$ pela sequiência $\mathrm{NML}+\mathrm{V}_{\text {in }}$ (+ Adị) + de + FN;

b) substituindo NML + Vin pelo nominal derivado;

c) especificando o artigo.

Tivéssemos, então:

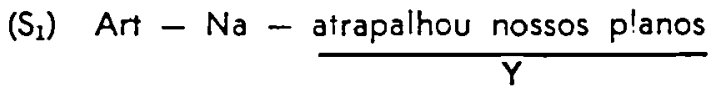

$\left(S_{2}\right)$ Os meninos - pass - vir

obteríamos, por (GT 7 ,

$$
\text { FN } T \text { Vin }
$$

$\left(S_{3}\right) \frac{A-\text { vinda dos meninos }}{\text { Art } N M L+V i n+\text { de }+F N}-\frac{\text { atrapalhou nossos planos }}{\mathrm{Y}}$

Vejamos, agora, como uma análise assim formulada daria conta do complexo de relaçōes de (6). Comecemos por (6.b) - relação entre os constiluintes duma estrutura - e (6.c) - relações entre estruturas.

(1) A vinda dos meninos (..)

(2) A destruição da cidade pelos inimigos (...) 
seriam obtidas transformacionalmente de estruiuras subjacentes senienciais. FNs como (1) e (2) seriam versōes nominais de sentenças (cf. Lees, op. cit.: 54): num determinado níve: de análise, a estrutura que subjaz a (1) ou a (2) é idêntica à que subjaz respectivamente a (4) ou (5),

(4) Os meninos vieram

(5) Os inimigos destrufram a cidade.

Sendo idêntica a descrição estrutural num dełeiminado nível e sendo aí o pon:o onde se definem as relações entre os constituintes, é possível ao modelo - com uma só estrutura abstrała e com o recurso da regra transformacional - dar conta da identiddae de S e FN quanto ao tipo de relações entre seus constíuinies (6.b); e dar conta da relação entre $S$ e FN (6.c).

Restaria, então, a relação entre itens lexicais (6.a).

O mcdelo que esiamos considerando, não supõe um nível especificamen'e mo:fológico e procura dar conta dos aspectos morfológicos por meio de uma combinação de recursos sintáticos e fonológicos o surgimento dum nominal na estrutura se dá como consequiência da aplicação da regra transformacional de nominalização, a qual cria uma subseqüência $\mathbf{N M L}+\mathbf{V}$ que - segundo Lees (op. cit.: 68) - produzirá mais tarde nominais de:ivados ("The nominalizing morpheme - NML will later produce derived nominals in -tion, -ity, men\}, etc.").

Foder-se-ia colccar - como problema relevante - a forma que - nominal vai ter, i e., a questão de saber como determinamos a escolha dos sufixos.

Digamos que o modelo, neste ponto, peca por omissão: ao tenlar suprimir um nível especificamente morfológico, a'ribuindo à sintaxe e j fonologia as tarefas da morfolgoia, ele não foi às últimas conseqüências destã opção. Embora proponha recursos para relacionar $\mathrm{S}$ e FN, ele não os fornece para explicar fatos como
a) cassar - cassação - "cassamento
b) casar - "casação - casamento
c) ordenar - ordenação - o:denamento
d) ler - leitura

i.e., ele não explicía o "mais ta-de" (la.ler) da frase de Lees citada 
anteriormente ("The nominalizing morpheme - NML will produce derived nominal in -tion, -ity, -ment, etc.")

Parece claro que não basta dizer que cassação é produzido como consequiência de se aplicar a transformação de nominalização a uma estrutura sentencial subjacente com 0 verbo cassar. E preciso, tamkém, ter recursos para predize: fatos como os que estão em (12), os quais, aparentemente envolvem processos não regulares ou bastante complexos. A questão da derivação morfológica permanece em aberto.

Outro fato interessante é que numa g:amática do português, o nominal deve entrar na estrutura aincla no componente sintático: em português, é preciso aplicar a regia de concordância (Nome-Artigo e Nome-Adjefivo); a concordância é um fenômeno sintático e vai clepender da forma que assumirá o nominal (a cassação/ o casamento); logo, esta forma deve ser especificada nos limites do comporiente sintático.

Este fato causa um certo transtorno a um modelo que pretenda deixar para a fonologia a especificação da forma do nominal.

Vejamos, agora, como ficaria uma análise transformacionalista de (1) e (2), incorporadas ao modelo as reformulações teóricas propostas por Chomsky (1965).

Neste último tex:o (cap. 3), argumenta-se a favor do abandono das transfo:maçōes generalizadas e se atribui às regras de reescritura do subcomponente categorial da base a propriedade de introduzir o símbolo $\mathrm{S}$ à direita da flecha, o que permite o reinício da aplicação das regras: a recursividade deixa de ser tarefa do subcomponente transformacional e passa para a base (cf. Chomsky, 1965: 134).

O abandono das transformaçōes generalizadas não invalidou a proposta de lees no que diz respeito aos seus princípios fundamentais, i.e., à idéia de uma anáise transformacionalista de (1) e (2) (obter $(1)-(4)$ e (2)-(5) de idênficas estruturas profundias).

As propostas do presente modelo para dar conta do complexo de relações de (6) - especialmente de (6.b) e (6.c) - são, assim, praticamente as mesmas do modelo anterior: sendo uma $\mathrm{S}$ e uma FN - ambas de superfície - relacionadas atribui-se a ambas uma estrutura profunda (EP) idêntica. Neste nivel de representação (EP), se definem (e se definem uma só vez para $S$ e FN, já qua ambas derivam da mesma EP) as funçōes dos constituintes, as relaçōes en- 
tie eles, bem como as restrições de seleção. $O$ que se tinha de fazer era adaptar a análise de Lees ao novo mode'o.

Apesar disto não parece haver nenhum trabalho que tenha explicitado uma tal análise. Fraser (1970) e Newmeyer (1970) usam - modelo para tratar de certos nominais de ação do inglês (John's driving of the car), mas não especificamente do tipo que estou abordnádo neste trabalho, salvo pequena referência em Newmeyer (op. cit.: 413-4), a qual é de pouco auxílio por excessivamente programática. Votre (1974) também não oferece apoio, pois, embora tente formular uma análise transfo:macionalista dos nomes derivados de base verbal, aceitando - as que parece - o modelo de Chomsky (1965), não opera com todas as reformulações introduzidas por este último texto; e, seguindo Ruwet (1967) postula a transformação de nominalização como uma transformação generalizada, à moda de Lies (1960). Comparemos os dois textos:

- Ruwet (op. cit.: 189): "Consideremos primeiramente o caso mais simples, o dos substantivos formados a partir de verbos intransitivos. A frase /11/ a chegada de Pedro surpre. endeu João pode ser descrita como produto de uma transformação generalizada que opera sobre as sequiêncisa subjacentes às frases Pedio chegou e Alguma coisa surpieendeu João".

- Votre (op. cit.: 70): "Na Tnomin, como já vimos, uma oração se converie em um nome ou em um sintagma nominal. Quando estão em jogo duas orações, a Tnomin se formaliza pela operação que encaixa uma versão transformada de uma oração constituinte no lugar de um nome ou de um sintagma nominal na oração.

\section{EX.: EU ACREDITAR $X$}

\section{Pedio SOFRER}

EU ACREDITAR no sofrimento de Pedro".

Tentemos formular então, uma aná'ise de

(1) A vinda dos meninos (alrapalhou nossos planos) com base em Chomsky (1965), utilizando o seguinte fragmento de gramática:

(13) $S \rightarrow$ FN FPred

$$
\mathrm{FN} \rightarrow(\text { Det) } N(S)
$$




$$
\begin{aligned}
& \text { Det } \rightarrow \text { (Pré-Art) Art (Pós-Art) } \\
& N \rightarrow[ \pm \text { Abstrato }] \\
& \text { FPred } \rightarrow \text { Aux FV } \\
& \text { Aux } \rightarrow T \text { T } \\
& F V \rightarrow V(F N) \\
& T \rightarrow \quad \text { pre } \\
& \text { Art } \rightarrow \text { [ } \pm \text { def }]
\end{aligned}
$$

(a) - Sendo a estrutura profunda

(14) (VIDE ANEXO 1)

(b) - e as regras:

R.1: Descriçăo Estrutural (DE)

$X-F N-A u x-V-Y$

$$
\begin{aligned}
& \Rightarrow \\
& \begin{array}{lllll}
1 & 2 & 3 & 4 & 5
\end{array} \\
& \text { Mudança Estrutural (ME) } \\
& 1 \varnothing \varnothing \mathrm{NML}+4 \mathrm{de}+25
\end{aligned}
$$

Condição: 234 são subseqüências duma S encaixada

As diversas mudanças sintetizadas nesta regra são:

a) inse:ir NML junto a $\mathrm{V}^{11}$;

b) apagar Aux;

c) pospor $F N$ a $N M L+V$;

d) inserir de antes de FN.

R.2: DE: Art $-\mathrm{N}-\mathrm{NML}+\mathrm{V}+\mathrm{de}+\mathrm{FN} \mathrm{Y}$

$$
\begin{aligned}
& \text { ME. } \begin{array}{cccc}
1 & 2 & 3 & 4
\end{array}=> \\
& \text { (a vírgula está para juntar } 3 \text { sob } 2 \text { ) } \\
& \text { Cond.: N está desdobrado em +abstrato }
\end{aligned}
$$

(c) obieríamos, então, a estrutura supe:ficial (substituindo $\mathbf{N M L}+\mathbf{V}$ pelo nominal corresponden e; e fazendo a concordância Nome-Artigo):

(14) (VIDE ANEXO 2) 


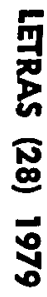

A NEXO 1

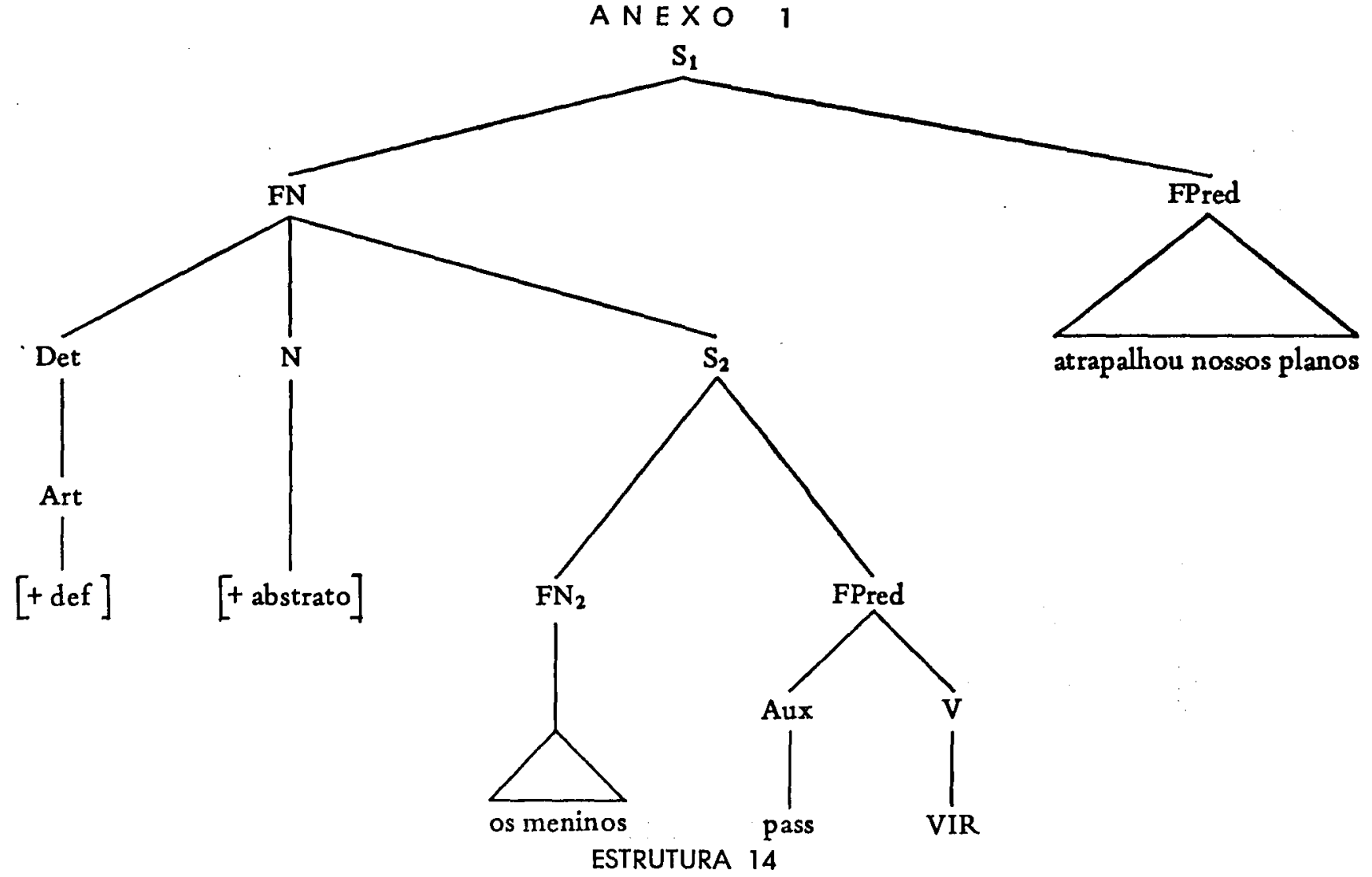




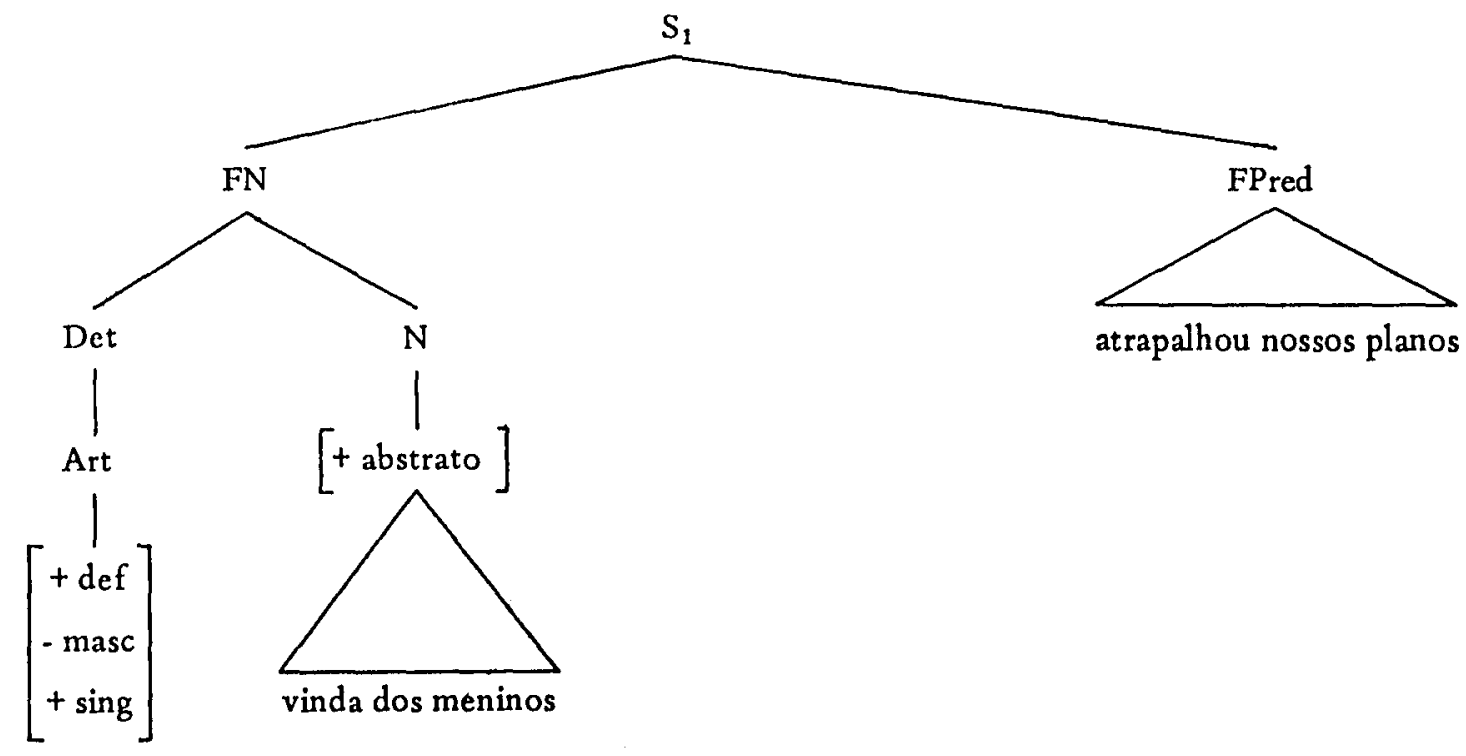


Em Chomsky (1965), cap. 4, § 2.3.: 184 e seg.), se chama a atenção para os problemas que uma gramática gerativa enfrenta ao tentar dar conta dos processos de derivação, justamente por serem eles, na maior parte, esporádicos ou semiprodutivos.

A tarefa - segundo Chomsky - é mais simples, se for possível mostrar que o proceso é regular, como no caso dos nomes derivados de verbos: a regulaiidade do processo sugere uma solução transformacionalista. ${ }^{12}$

Embora o processo seja regular, os fatos parecem mostrar que a forma do nominal - a forma que substitui $\mathbf{N M L}+\mathbf{V}$ - é idios'sincrática - conforme se discutiu anteriormente a propósito dos exemplos (12).

Em Chomsky (1965: 184), se aceita o caráter idiossincrático da forma do nominal e se dá, num certo sentido, uma resposta à questão morfológica (a qual tinha ficádo em aberto no modelo an'erior), atribuindo ao léxico a tarefa de registrá-la sob a entrada do respectivo verbo, já que o léxico - no segundo modelo - é o repositório das propriedades idiossincráticas dos jtens lexicais (cf. Chomsky, op. cit.: $86-7$; 136; 142).

'Clearly, the word's destruction, refusal, etc. will not be entered in the lexicon as such. Rather, destroy and refuse will be entered in the lexicon with a feature specification that determines the phonetic form they will assume (by later phonological rules) when they apper in nominalized sentences".. (Chomsky, op. cit.: 184)

A análise por este segundo modelo continua considerando como irrelevante o estabelecimento dum nível especificamente mo:fológico: atribuem-se as tarefas da morfologia a uma. combinação de processos sintáticos e fonológicos acrescida da informação do léxico.

Observe-se, novamente, que a forma do nominal - numa gramática do português - não pode esperar o componente fonológico para ser esfecificada, na medida em que dela depende a correta aplicação da regra de concordância (Nome-Artigo; Nome-Adjetivo).

Talvez, a inserção da forma nominalizada do verbo se possa fazer por uma reaplicação da regra lexical, dentro do componente sintático. 
Cediquemos um pouco mais de nossa afenção ao problema da derivação morfológica.

Este é um assunto bastante complexo para uma gramática gerativa, em razão da imprevisibilidade - ao menos aparente - na es. colha dos afixos derivacionais (p. ex., a escolha entre çăo e -mento para se obter nomes derivados de verbos). A complexidade co

assunto limita os teóricos gerativos, ao menos po: ora, a um mero arranjo taxonômico dos dados (cf. Chomsky, op. cit.: 192). E nesta linha que está, por exemplo, Chapin (1970), onde se faz uma listagem de prob'emas interessantes a serem considerados por um estudo qualquer que pretenda ulirapassar a me:a taxonomia.

A teoria, contudo, precisa de informação sobre a estrutura interna das palavras, quer para dar conta da competência do falante fara criar e interprelar palavras novas, quer para o funcionamento de outras partes da gramática.

Neste segundo caso, a teoria tem sido obrigada - a falta de estudos explícitos da derivação lexical - a trabalhar assumindo "a priori" este tipo de informação. E o que ocorre, por exemplo, na seguinte afirmação em Chomsky \& Halle (1968:33): "The word theatrical..., is CLEARLY DERIVED from theater...". O destaque de CLEARLY DERIVED é meu e a pergunta é: como incorporar à gra. mótica este "a priori", i.e., que condiçōes devem ser definidas para se saber quando uma palavra é claramente derivada de outra.

Muitos aspec'os do estudo dos padrōes de acento em inglês, em Chomsky \& Halle (op. cit.: 29 e seg.), envolvem informação morfológica (esirutura interna da palavra): a colocação do acento em certas palavras supōe que se especifique a sua estrutura inteina para permitir que a aplicação ciclica das regras produza os resultados corretos. Outra vez, resta saber quais os critérios explícitos de especificação de estrutura interna de palavras.

Em Hooper (1973:72), discutem-se os prozessos morfológicos em termos de processos produtivos e não produtivos, tirando - $\mathrm{co}$ mo conseqüêencia desta distinção - a conclusão de que as palavras cbtidas por processos produtivos nāo serão listadas no léxico. Assumem-se, portanto, que tais processos sejam explicitado em algum fonto da gramática, sem o que nāo é possivel saber que palavras são ou não incluídas no léxico.

Em sintese, o p:oblema básico - no assunto derivação lexical - 
parece ser explicitar os recursos de engendramento e descrição estrutural de palavras.

Vejamos, agora, algo a respeito do Auxiliar.

A presença do Auxiliar na estrutura profunda correspondente a uma estrutura superficial com nominal pode ser justificada pelo caráter facultativo que primeiro se tentou atribuir à transformação de nominalização. Esła facultatividade emergiu da intenção de se incorporar ao modelo gramatical a sinonímia frasal presente em

(15) Ele confirmou que os meninos virão

(16) Ele confirmou a vinda dos meninos

por meio duma única estrutura profunda, da qual se obteria (15) ou (16), dependendo da aplicação ou não da regra que nominalizaria sentenças encaixadas. No caso de a regra ser aplicada, o Auxiliar deveria ser apagado por não ter realização de superfície em frases noninais. A não realização superficial do Auxiliar não implica, contudo, sua não ocorrência na estrutura profunda. Parece necessário prever tal ocorrência para se poder justificar a ambigüidade de (16), frase que pode corresponder, numa leitura semântica, a (15) e, em outra, a

(17) Ele confirmou que os meninos vieram.

Julho/78

1. A respeito do título Nomina'ização, comentários mais detalhados na nota 7 .

Embora esteja concentrada a atençäo sobre os nominais dos exemplos como (1) e (2), é importante ressaltar que há outros casos envolvidos sob o tífulo Nominalização. Dentre estes: as est uturas que contêm nominais de agente como inventor em o invetor da roda; e de resultacio como invento em o invento de João. Ver, a respeito destes tipos de estrutura, Lakoff (1970, cap. 5, itens 5.2 e 5.13 ; e cap. 6 , itens $6.41-5$ ) e McCawley (1968a: 267 e seg.).

Igualmente excluo estruturas contendo nominais relacionados com adjetivos (crueldade em a crueldade de João; a valentia em a valentia do coronel).

Na nota 3 faz-se referência a um outro caso excluido de consideração aqui.

2. A caracterização que está a seguir é bastante informal, porque estou apenas delineando o problema das estruturas sob análise, fazendo-o com traços bastante gerais: dou característicar: informais para - a partir delas - poder trabalhar mais acuradamente no decorrer do texto.

Quando a seguir no texto falo em relação, o termo está empregado num sentido amplo equivalente infuitivamente a vinculação, ligaçäo. Ao apresentar certas relaçōes em termos de agante/ação, açäo/paciente, faço-o também informalmente: primeiro, r.orque os termos ação, agente, paciente não têm conceito explícito em lingüística; e, segundo, porque está me interessando destacar o fato de haver um tipo qualquer de relação entre os const tuintes de uma estrutura, sem especificar cada tipo de relação em particuiar.

As abreviaturas que estão no texto, a seguir, devem ser assim entendidas: Art. artigo; $\mathrm{N}$ - nome; FN - frase nominal; $\mathrm{S}$ - sentença. 
Chamarei de nominal ao nome relacionado morfologicamente com outra palavra (com um verbo, no caso especifico deste estudo).

3. E importante destacar que os nominais em relevo aqui são os nominais de ação, assim cnamados pelo fato de serem (como seus parentes verbais) referentes duma ação. $E$ aqui chegamos a um limite de explicitaçāo: nāo existe, em iingüistica, nenhum conceito satisfatório de açāo. Isto nos obriga a apelar a nossas infuiçōes, visando a deixar claro - no limte do possivel - quais estruturas estāo sendo enfocadas. Com o objetivo de avivar nossa intuiçāo, ponho em confronto uma estrutura cm um nominal de ação e outra com um nominal de sentimetro, este também relacioado com um verbo, mas a estrutura que o contém é diferente daque as exemplificadas em (1) e (2), como se pode ver a partir de (a) e (b):

(a) O amor de João por Maria (nos alegra)

(b) A destruiçäo de João por Maria (nos alegra)

Embora a estrutura superfitial de (a) e (b) seja a mesma (Art. - N - de - FN - por - FN), a relaçāo que se podo definir entre João e amor (digamos, Joáo é agente do amor) é diferente daquela entre Joāo e destruição (Joāo, aqui, é o paciente da destruiçāo); tal corro entre Maria e amor (Maria é o paciente do amor) e entre Maria e déstruição (Maria é agente da destruiçāo), fato que fica patente se compararmos duas sentenças equivalentes a (a) e (b):

(a) Joäo ama Maria...

(b') Maria destrói João...

As estruturas com nominais de sentimento - (a), nos exemplos discutidos - estão excluidas deste estudo. A respeito de'as, ver Ruwet (1967:188 e seg., especialmente p. 194, item 5.3.2.2).

\section{Oração, na terminologia tradicional.}

5. "Denomina-se FAMILIA DE PALAVRAS o conjunfo de todas as palavras que se agrupam em torno de um radical comum, do qual se formaram pelos processos de derivaçäo ou de composiçäo". (Cunha, 1970:42). Nestes termos, conhecimento e conhecer pertencem à mesma familia: à do radical CONHEC.

6. Uma ană ise em con'tifuintes imediatos não se importava com as relaçōes entre estruturas como (1-(2)) e (4) - (5): cada uma recebia uma descriçāo estrutural diferente.

$\mathrm{Na}$ lingǘśtica gerativo transformacional tais relaçōes passaram a ser relevantes: o falante as percebe; e a gramática - procurando ser um modelo da competência do fa. lante - deverá expressállas.

O nome lingüistica gerativo-transformacional é, hoje, genérico demais, na medida em que sob ele coexistem diferentes posiçōes teóricas (especialmente no que se refere à elaboração de modelos. Neste trabalho, estou assumindo a teoria mais próxima de Chomsky, cuja posição quanto à organi-ação da gramática pode ser assim resumida:

- a gramática é um mecanismo composto de três componentes: o sintático, o semântico e o fonológico. Destes, o primeiro é o central por ter o poder de engendrar um conjunto infinito de objetos formais - cada um com sua descriçāo estrutural que permitem relacioar som e significado numa lingua qualquer.

O primeiro é, portanto, o componente gerativo, enquanto os outros dois são interpretativos. Vale dizer, es componentes semântico e fonolófico desempenham o papel de passar as estruturas sintáticas para sistemas de reoresentação semântica e fonética.

Estas assunçōes têm se mantido constantes em Chomskv. nāo tendo sido afetadas pelas continuas reformulaçōes do seu modelo ( $f$. Chomsky, 1965, cap. 1, item 3; - 1967:184-5; 1968:183-7).

Obsevaçäo terminológica: em geral, cs termos técnicos presentes na discussäo que se segue (estrutura profunda, estrutura superficia', bass, subcomponente transformacional, léxico, transformacāo...) sz̃o tomados como o conceito corrente nos trabalhos de lingüistica gerativo-transformacional e que foram formulados em Chomsky (1965). 
7. O termo nominalização, é tomado como designativo dum conjunto de regras do sub-componente transformacional da gramática. Este recebe - como entrada - uma estrutura profunda contendo encaixada uma seqüêencia dominada por $S_{\text {; }}$ e dá - como saída, aplicadas as regras antes mencionadas - esta mesma seqüência transformada numa estrutura nominail.

A hipótese lexicalista abandona este conjunto de regras. Com isto, ela empobrece - subcomponente transformacional (i.e., diminui-the o número de regras), enriquecendo, em contrapartida, o subcomponente categorial (aumenta-the o número de regras).

Em trabalhos lexica istas - como Basilio (1977) - continua-se a empregar o termo nominalizaçāo, apenas que designando um processo morfológico e, não, um conjunto de regras do subcomponente transformacional.

8. Além dos nominais derivados de verbos como vinda e destruição, Lees estuda outros nominais derivados de verbos (inventor); nomes derivados de adjetivos (consfância) nomes compostos (bejiaflor).

9.As relações sintáticas, no caso, são as que definem funções como sujeito, objoto, .... funçōes estas que terão formulação mais explícita para a teoria em Chomsky (1965, cap. 2).

10. A respeito de transformaçōes generalizadas, ver Chomsky (1957:72 e seg.); -__ (1962:229 e seg.); a propósito do problema da interpretaçāo semântica das estrufuras obtidas via estas transformaçōes, ver Katz \& Postal (1964:12 e 48-53).

11. Nesta formulação exemplificativa, estou assumindo que a transformação de nominalização é facultativa. Em Chomsky (1965:235, n. 40), sugere-se que 0 indicador sintagmático de base já contenha, na $\mathrm{S}$ encaixada, o morfema de nominalização (NML). Neste caso, a transformaçäo seria obrigatória.

12.Em Chomsky (1967:188), vai se procurar mostrar que, de fato, o processo não é assim reguiar em inglês, o que se toma como um dos argumentos para á elaboração da hipótese alternativa.

Almeida, Napoleão Mendes de. 1967. Moderna Gramática Expositiva da Língua Portuguesa. 20. ed. S. Paulo, Saraiva.

Basilio, Margarida Maria de Paula. 1977. Aspects of tse Structure of the Lexicon: Evi-

dence from Portuguese. Dissertação de doutorado, Faculty of the Graduate School of the University of Texas, Austin, inédito.

B.erwisch, M. \& Heidolph, K.E. (eds.) 1970. Progress in Linguistics: A Collection of Papers. The Hague, Monton.

Campbell, M.A. et alii (eds.) 1970. Papers from the Sixth Regional Meeting, Chicago

Linguistic Society. Chicago, Chicago Linguistic Society.

Chapin, Paul G. 1970. "On Affixation in English". In: Bierwisch \& Heidolph (eds.): 51-63.

Shomsky, Noam. 1957. Syntactic Structures. The Hague, Mouton.

- 1962. "A Transformational Approach to Syntax". In: Fodor \& Katz (eds.): $211-45$.

-1965. Aspects of the Theory of Syntax. Cambridge (Mass.), The MIT Press.

. 1967. "Remarks on Nominalization". In: Jacobs \& Rosenbaum (eds.):184-221.

1968. "Deep Strucuture, Surface Structure, and Semantic Interpretation". In:

Steinberg \& Jakobovits (eds.): 183-216.

- \& Halle, M. 1968. The Sound Patfern of English. New York, Harper \& Row.

Cunha, Celso. 1970. Gramática Moderna. Belo Horizonte, Bernardo Álvares. 
Fodor, J.A. \& Kalz, JJ. (eds.) 1964. The Structure of Language: Readings in the Philosophy of Language. Englewoods C.iffs, Prentice-Hall.

Fraser, Bruce. 1970. "Some Remarks on the Action Nominalization in English". In: Jacobs \& Rosenbaum (eds.): 83-98.

Hooper, Joan B. 1973. Aspects of Nafural Generative Phonology. Dissertaçāo de doutoramento, University of California, Los Angeles.

Jacobs, R.A. \& Resenbaum, P.S. (eds.) 1970. Readings in English Transformational Grammar. Woltham (Mass.), Ginn.

Jespersen, Otto. 1924. The Philosophy of Grammar. Trad. francesa: Paris, Les Editions de Minuit, 1971.

Katz, J.J. \& Postal, P.M. 1964. An Integrated Theory of Linguistic Descriptions. Cambridge (Mass.). The MIT Press.

Lakoff, George. 1970. Irregularity in Symtax. New York, Holt, Rinehart and Winston.

Lees, Robert B. 1960. The Grammar of English Nominalizations. The Hague, Mouton.

lima, C.H. Rocha. 1972. Gramśtica Normativa de Lingus Portuguesa 15. ed. ref. Rio, José O.ympio.

Lyons, John 1968. Introduction to Theoretical Linguistics. Cambridge (Eng.) Cambridge University Press.

McCawley, James D. - 1968. "Lexical Insertion in a Transformational Grammar Without Deep Structure". Trad. espanhola: Sánchez de Zavala (comp.): 259-75.

Newmeyer, Frederick J. 1970. "The Derivation of the English Action Nominalization". In: Campbell et alii (eds.): 408-15.

Ruwet, Nicolas. 1967. Introduction a la Grammaire Génerative. Trad, portuguesa: S. Paulo, Perspectiva, 1975.

Súnchez de Zavala, Victor (comp.) 1974. Semántica y Sintaxis an la Lingüistica Trans. formatória, I: Comienzos y Centro de la Polômica. Madrid, Alianza.

Stoinberg, D.D. \& Jakobovits, L.A. (eds.). 1971. Semantics: An Interdiscipiinary Reader in Philosophy, Linguistics and Psychology. Cambridge (Eng.), Cambridge University Press.

?orres, Artur de Almeida. 1961. Modoma Gromátics Expositiva da Língus Portuguess, 20. ed. rev. e amp. Rio, Fundo de Cultura.

Votre, Sebastiāo Jo:ué. 1974. Substantivos Derivados de Bases Verbais: Abordagem Transformacional. Dissertação de Mestrado, PUC-RS, Porto Alegre, inédito.

\section{SUMMARY}

This paper is a presentation of some problems related to the description of some Pertuguese nominalized NPs. Based on the data, some generative modeis to treat the phenomena are discussed.

\section{RESUMO}

E:te t:abalho apresenta alguns problemas relacionados com a descrição de algumas estruturas nominalizadas do portuguès. Com base nos dados coletados, discutem-se aiguns modeios gerativos que tratam do problema. 